Supporting Information to

\title{
Agonists and Partial Agonists of Rhodopsin: Retinal Polyene Methylation Affects Receptor Activation
}

Reiner Vogel, Steffen Lüdeke, Friedrich Siebert, Thomas P. Sakmar, Amiram Hirshfeld, and Mordechai Sheves

Figure A1

Meta II and Meta I of 13-demethyl isorhodopsin. Meta II (A) and Meta I (B) FTIR difference spectra photoproduct minus dark state of 13-demethyl Iso (black spectra) were obtained at $20^{\circ} \mathrm{C}$ at pH 4.0 (A) and at $0{ }^{\circ} \mathrm{C}$ at $\mathrm{pH} 9.5$ (B), respectively, and are compared to respective spectra of native Iso (gray spectra) obtained at $10{ }^{\circ} \mathrm{C}$ at $\mathrm{pH} 5.0(\mathrm{~A})$ and at $0{ }^{\circ} \mathrm{C}$ at pH 9.5 (B). With a pK of 5.9 (C), the $\mathrm{pH}$ dependence of Meta I/Meta II of 13-demethyl Iso corresponds to that obtained with 13-demethyl rhodopsin (pK 6.0), as to be expected.
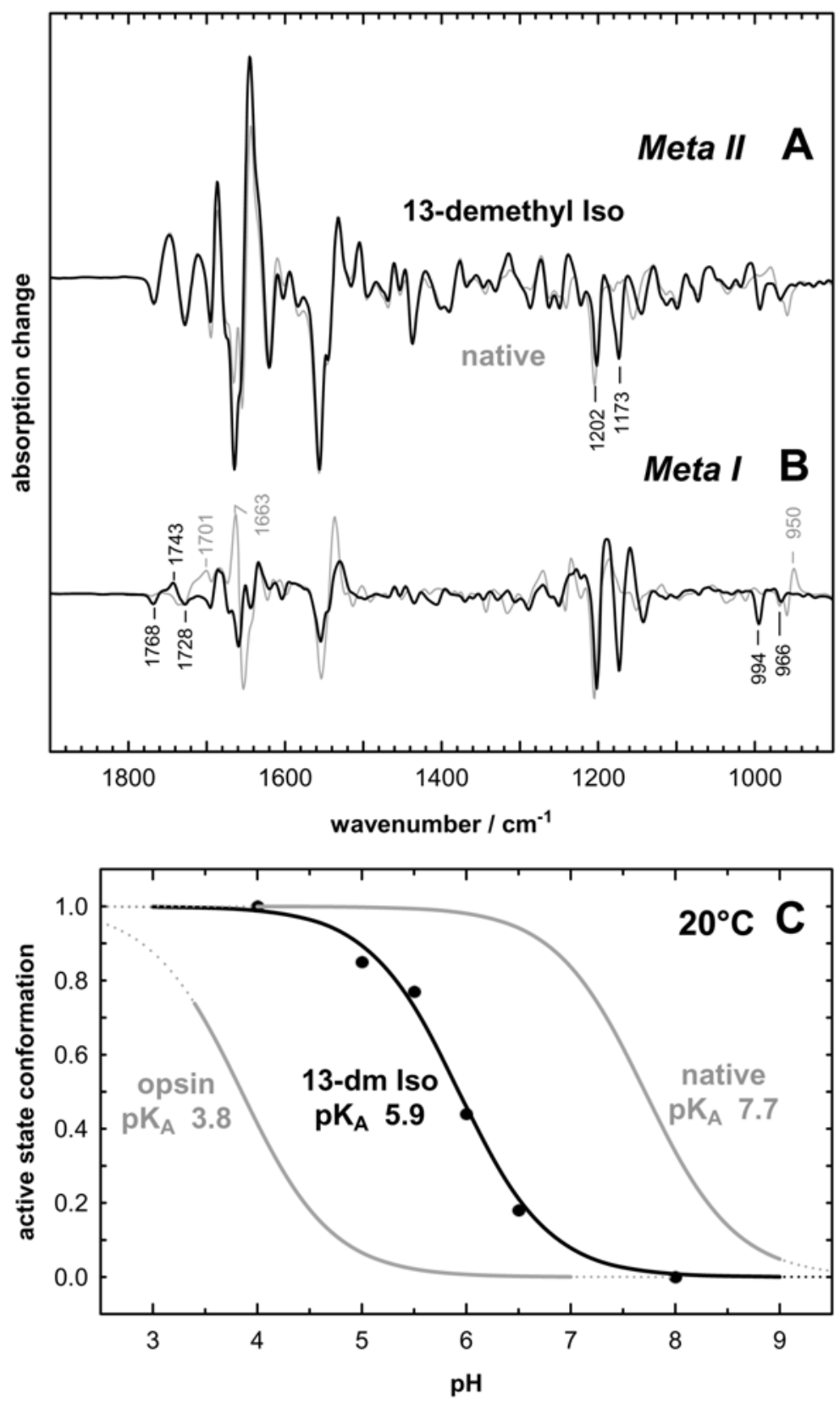
Figure A2

Photoreaction of 13-demethyl Iso solubilized in dodecyl maltoside (DM). 13-demethyl Iso was solubilized in 1\% DM and its photoreaction (30 s with a $475 \mathrm{~nm}$ long-pass filter) was monitored in 100 $\mathrm{mM}$ buffer, $100 \mathrm{mM} \mathrm{NaCl}$, at $10^{\circ} \mathrm{C}$ by UV-visible spectroscopy. Both at pH 5.0 (A) and 9.0 (B), as well as at intermediate $\mathrm{pH}$ values (not shown), a $380 \mathrm{~nm}$ photoproduct indicative of Meta II was formed.

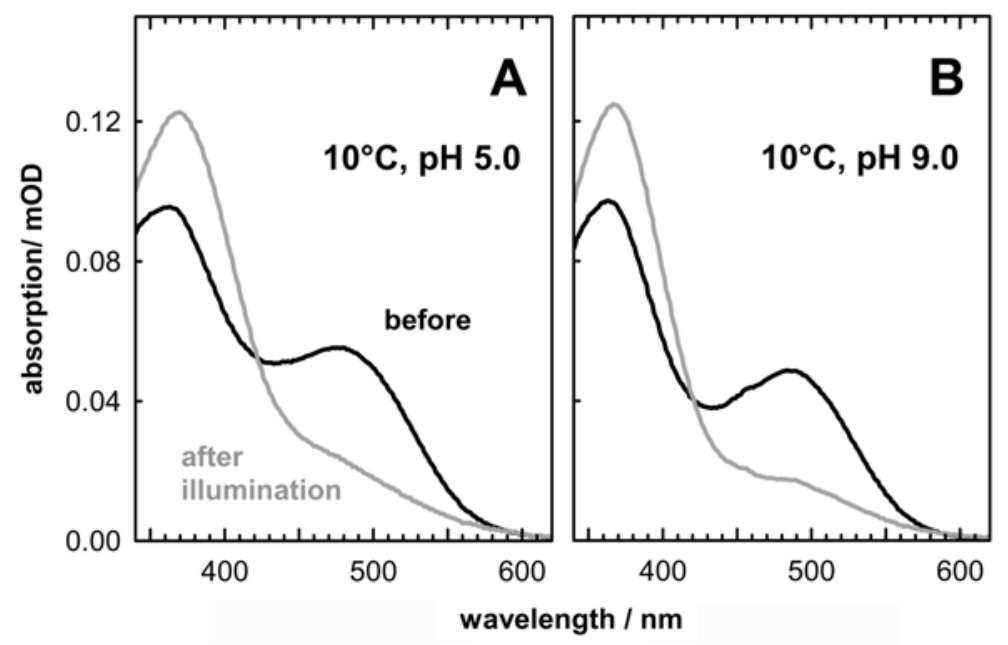


Figure A3

Temperature dependence of the $\mathbf{p K}_{\mathrm{A}}$. The $\mathrm{pK}_{\mathrm{A}}$ values of 13-demethyl rhodopsin, 9-demethyl isorhodopsin, 10-methyl isorhodopsin, 12-methyl rhodopsin, and 14-methyl isorhodopsin were determined at $0{ }^{\circ} \mathrm{C}$ and $20{ }^{\circ} \mathrm{C}$ and are compared to the corresponding values of native pigment, 6.6 and 7.7 , respectively (gray dashed curves).
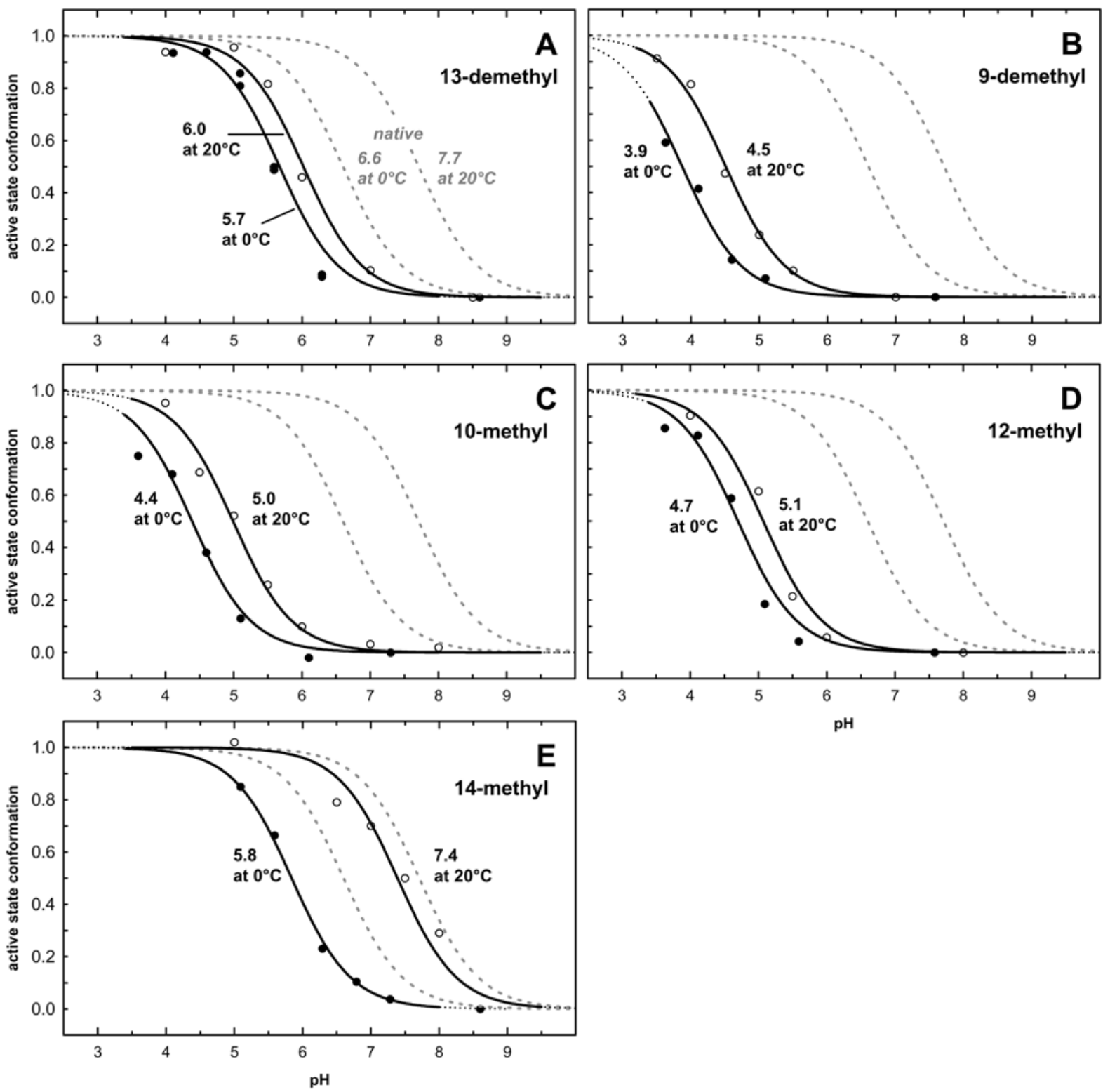

\section{E}




\section{Section A4: Calculation of $\Delta \mathrm{H}$ and $\Delta \mathrm{S}$}

In the following section we will derive equations to calculate the enthalpy change $\Delta \mathrm{H}$ and the entropy change $\Delta \mathrm{S}$ of the Meta I/Meta II equilibrium (MI and MII in the following) from the measured $\mathrm{pK}_{\mathrm{A}}$ values of the transition at two different temperatures $T_{1}$ and $T_{2}$. Starting from the reaction

$\mathrm{MI}+\mathrm{H}^{+} \leftrightarrow \mathrm{MII}$

we derive

$\frac{[\mathrm{MII}]}{[\mathrm{MI}]\left[\mathrm{H}^{+}\right]}=\mathrm{K}_{\text {eq }}=\mathrm{e}^{-\Delta \mathrm{G} / \mathrm{RT}}$, with $\Delta \mathrm{G}=\Delta \mathrm{H}-\mathrm{T} \Delta \mathrm{S}$, where $\mathrm{K}_{\text {eq }}$ is the equilibrium constant between $\mathrm{MI}$ and $\mathrm{MII}, \mathrm{T}$ is the absolute temperature, $\mathrm{R}$ is the gas constant, and $\Delta \mathrm{G}$ is the Gibbs free energy change of the transition.

Taking the logarithm of this equation yields

(1) $\quad \ln \mathrm{K}_{\text {eq }}=\frac{-\Delta \mathrm{G}}{\mathrm{RT}}=\frac{-\Delta \mathrm{H}}{\mathrm{RT}}+\frac{\Delta \mathrm{S}}{\mathrm{R}}$

Solving this equation for $\Delta S$ yields

(2) $\Delta \mathrm{S}=\mathrm{R} \ln \mathrm{K}_{\mathrm{eq}}+\frac{\Delta \mathrm{H}}{\mathrm{T}}$.

Evaluating (1) for two different temperatures $T_{1}$ and $T_{2}$ yields

$\ln \mathrm{K}_{\mathrm{eq} 1}=\frac{-\Delta \mathrm{H}}{\mathrm{RT}_{1}}+\frac{\Delta \mathrm{S}}{\mathrm{R}}$ and $\ln \mathrm{K}_{\mathrm{eq} 2}=\frac{-\Delta \mathrm{H}}{\mathrm{RT}_{2}}+\frac{\Delta \mathrm{S}}{\mathrm{R}}$.

Assuming $\Delta \mathrm{H}$ to be independent of temperature over the considered range, we can form the difference between these two expressions

$$
\begin{aligned}
& \operatorname{InK}_{\text {eq } 2}-\ln K_{\text {eq } 1}=\frac{-\Delta H}{R}\left(\frac{1}{T_{2}}-\frac{1}{T_{1}}\right) \text { and thus } \\
& \text { (3) } \Delta \mathrm{H}=-\mathrm{R} \frac{\ln \mathrm{K}_{\text {eq } 2}-\ln \mathrm{K}_{\text {eq } 1}}{\frac{1}{\mathrm{~T}_{2}}-\frac{1}{\mathrm{~T}_{1}}}=\mathrm{R}\left(\ln \mathrm{K}_{\text {eq } 2}-\ln \mathrm{K}_{\text {eq } 1}\right) \frac{\mathrm{T}_{1} \mathrm{~T}_{2}}{\mathrm{~T}_{1}-\mathrm{T}_{2}} .
\end{aligned}
$$

To derive the equilibrium constants $\mathrm{K}_{\text {eq }}$ from our data, we use the Henderson-Hasselbalch equation $\mathrm{pK}=\mathrm{pH}+\log _{10} \frac{[\mathrm{MII}]}{[\mathrm{MI}]}=\log _{10} \frac{[\mathrm{MII}]}{[\mathrm{MI}]\left[\mathrm{H}^{+}\right]}=\log _{10} \mathrm{~K}_{\text {eq }}$, which yields $\mathrm{K}_{\text {eq }}=10^{\mathrm{pK}}$ and (4) $\quad \ln \mathrm{K}_{\mathrm{eq}}=(\ln 10) \mathrm{pK}$, where $\mathrm{pK}$ is the $\mathrm{pK}_{\mathrm{A}}$ of the MI/MII equilibrium at a given temperature. Inserting (4) into (3) yields the following expression for $\Delta \mathrm{H}$ (with $\ln 10 \approx 2.303$ ) 
(5) $\Delta \mathrm{H}=\mathrm{R} \cdot 2.303 \cdot\left(\mathrm{pK}_{1}-\mathrm{pK}_{2}\right) \cdot \frac{\mathrm{T}_{1} \mathrm{~T}_{2}}{\mathrm{~T}_{1}-\mathrm{T}_{2}}$

Evaluating (2) at $T_{2}$ and insertion of (4) and (5) yields the following expression for the change of entropy of the transition

$$
\Delta \mathrm{S}=\mathrm{R} \ln \mathrm{K}_{\mathrm{eq}}+\frac{\Delta \mathrm{H}}{\mathrm{T}}=\mathrm{R} \cdot 2.303 \cdot\left(\mathrm{pK}_{2}+\left(\mathrm{pK}_{1}-\mathrm{pK}_{2}\right) \cdot \frac{\mathrm{T}_{1} \mathrm{~T}_{2}}{\left(\mathrm{~T}_{1}-\mathrm{T}_{2}\right) \cdot \mathrm{T}_{2}}\right)
$$

This expression can be simplified by algebraic transformations to

(6) $\Delta \mathrm{S}=\mathrm{R} \cdot 2.303 \cdot\left(\frac{\mathrm{pK}_{1} \mathrm{~T}_{1}-\mathrm{pK}_{2} \mathrm{~T}_{2}}{\mathrm{~T}_{1}-\mathrm{T}_{2}}\right)$

Turning back to (5), the experimental error of $\Delta \mathrm{H}$ stems largely from the error of $\mathrm{pK}_{2}-\mathrm{pK}_{1}$. The error for the single $\mathrm{pK}_{\mathrm{A}}$ values is estimated to be less than 0.2 units, being mostly due to difficulties in determining a pure Meta II state. As both $\mathrm{pK}_{1}$ and $\mathrm{pK}_{2}$ were derived with the same basis spectrum of Meta II for each pigment, the inherent error is a systematic error. We therefore estimate the error margin for the difference to be at maximum 0.2 units. This yields an absolute error for $\Delta \mathrm{H}$ of at maximum $15 \mathrm{~kJ} / \mathrm{mol}$. Turning to equation (2), $\Delta S$ consists of two terms, of which the second contributes predominantly to the error, such that the experimental error stems largely from the error in determining $\Delta \mathrm{H}$. The experimental error for $\Delta \mathrm{S}$ is therefore within approximately $54 \mathrm{~J} / \mathrm{mol} \cdot \mathrm{K}$. 
The retinals are shown as protonated Schiff bases of the isomers used for regenerating the modified pigments.

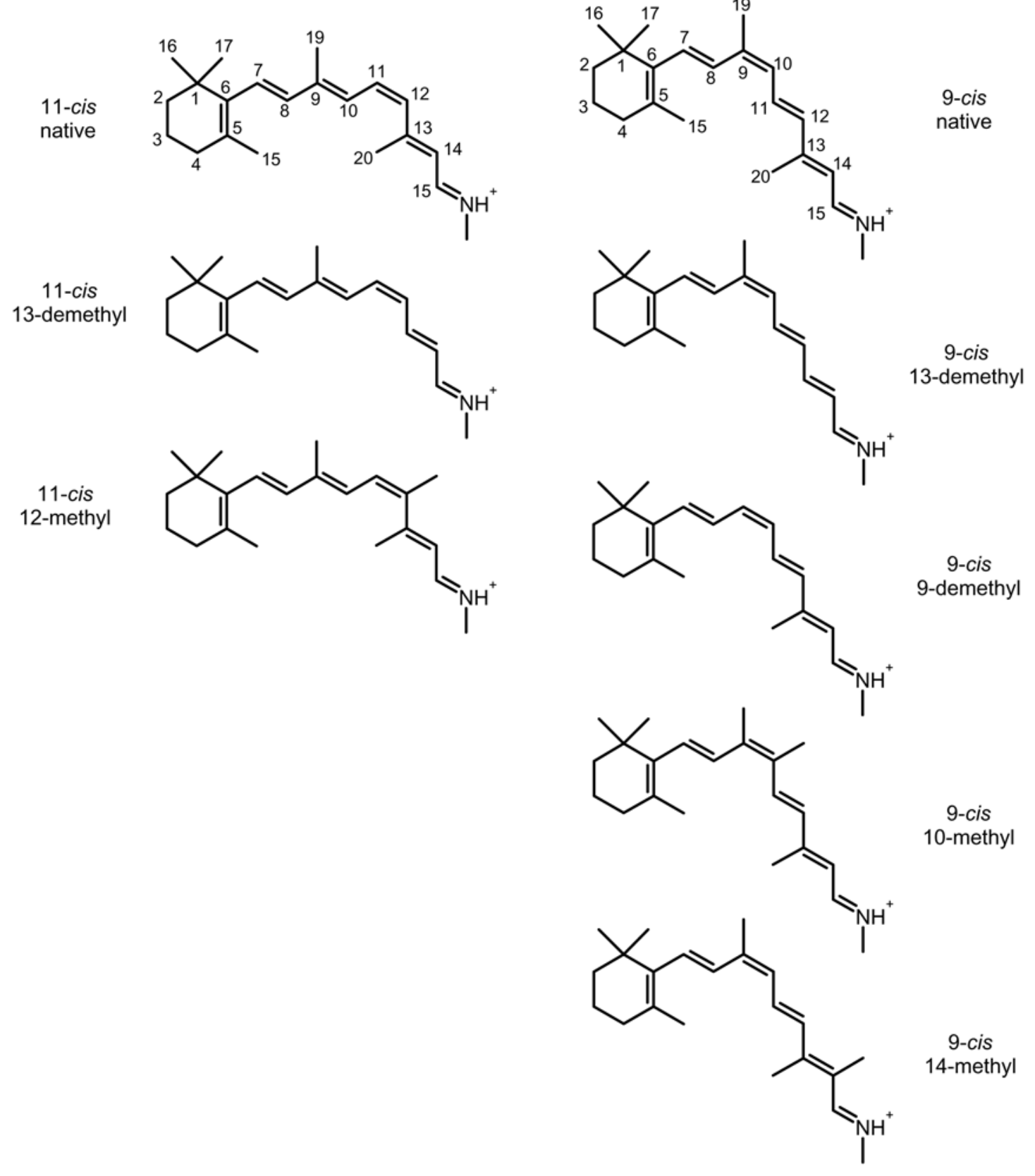

